\title{
INVESTIGATING VARIATION IN PULWOOD
}

\author{
by J. D. Hale, \\ Forest Products Laboratories \\ Forest Service, Department of the Interior, Canada.
}

$\mathbb{R}^{\mathrm{E}}$

ELATIVELY small variations in wood may be important in industrial processes. In the manufacture of paper, for example, if one supply of pulpwood averages a pound per cubic foot heavier than another its yield of pulp will normally exceed that of the lighter wood by about half a ton for each charge of a ten ton digester. This would constitute a favorable margin for the mill operating on the heavier wood and yet the difference in density between the two lots of pulpwood is well within the range of variation that may be noted in a single species (white spruce from two different sites for example). It would seem particularly desirable, therefore, that the operators of paper mills should know how the pulpwood on their limits varies so that they may plan the annual supply of pulpwood with the best possible accuracy regarding the yield and quality of pulp that it will produce.

In the course of investigating the normal variation in woods, the Forest Products Laboratories of Canada have undertaken a specific study of variation in the pulpwood species of eastern Canada. With the cooperation of the Canadian Pulp \& Paper Association in this study, the Forest Products Laboratories have, during the summer of 1935 collected samples of pulpwood for test from various pulpwood stands in Canada from western Ontario (Kenora) to Quebec and New Brunswick, and the material is now in the course of being tested at the Ottawa Laboratories.

Although wood is often rather variable it is by no means unique in this respect. Most other material, whether produced by nature or human manufacture, or by a combination of the two, show variation somewhat comparable to variation in timber. Wood, however, has such essential importance that it is desirable to know the range of its variation and how it varies within this range if such variation is sufficient to affect the wood's utility.

From the work of timber testing laboratories in the various countries, information on the average qualities of important commercial timbers has gradually accumulated. Consequently, by consulting appropriate tables it is possible to find how one kind of wood compares with another in its important properties. Naturally, the figures available are the averages of numerous tests. As

*Forest Service, Department of the Interior, Ottawa. 
a rule, however, such tables give little indication of the range of values encountered in testing a number of samples of the same species of wood, for the importance of knowing the normal variation within each species is just beginning to be generally appreciated, and considerable investigation will be required before adequate knowledge of the variation of the important woods is complete.

In studying the variation of wood the best common basis of comparison for all species appears to be the weight per unit volume of the wood at specified moisture content. As the weight per unit volume of wood at any moisture ce. . ent may be calculated conveniently from the basic specific gravity this property is suitable and convenient to use in practically all quantitative comparison of woods. (The basic specific gravity is the specific gravity based on the volume of wood when saturated and its weight when oven-dry). If, therefore, the basic specific gravity is determined for adequate samples of wood taken from various sites in different regions of Canada the results should indicate how the wood varies in weight under the various growing conditions ohtaining in the different localities of its habitat.

It is known that the yield of pulp is approximately proportional to the density of pulpwood. Also the mechanical properties of wood may he expressed as functions of a wood's density, so that in measuring the basic specific gravity, an indication of the important qualities of a wood may be obtained. It should, therefore, be possible for pulpwood operators, by determining the basic specific gravity of samples of wood growing in the significant types that compose their stands, to obtain thereby an indication of the quality of the wood in their limits that would greatly assist them in estimating closely the amount of wood required for a definite output of pulp.

With this as one of its objectives, the investigation of the Forest Products Laboratories was arranged so as to obtain samples of the pulpwoods of eastern Canada (white spruce, Picea glauca: black spruce, Picea mariana and balsam fir, Abies balsamea) in various localities from western Ontario to Nova Scotia. It is planned to obtain pulpwood samples from the black spruce type where this species is the chief component of the stand; from the softwoood type where balsam fir and the spruces occur together and from the mixed type where hardwoods form a considerable proportion of the stand. With a wide distribution of material from these representative types sampled at various regions in Canada it should be possible to note whether there is any general trend of variation in density of wood due to broad geographical or climatic conditions, and to relate the data obtained to wood of these species growing in comparable types in the various regions of their geographical range.

While it is important to note such variations in density of wond as may be 
found in trees from various localities, it is also most important in an investigation of such wide scope to discover what causes significant variations. The collectors therefore have studied each stand that has been sampled in order to record a good description and history of the stand with notes on its density (the percentage of ground shaded at noon), the species composing it, the slope, aspect, altitude, general topography, drainage, soil profile, ground cover, underbrush and small growth. With all possible detailed information about the stand sampled it should he possible to relate any significant variations in the weight of wood from various localities to the growth conditions responsible for such variations in the wood.

The matter of obtaining a representative sample is of course most inportant. The collector examines the stand carefully before deciding this point and, if the stand is to be sampled, makes an estimate of its composition by strip tallies to record the diameter classes of the important species. For each species sampled the collector fells five trees of each significant diameter class. Many pulpwood stands have a large proportion of the trees concentrated in a comparatively small range of diameter classes so that generally it has not been advisable in this investigation to take more than thirty trees of each species studied from any of the stands sampled.

Since the test material must be shipped to the Ottawa Laboratories for analysis, he samples are taken in the form of discs-complete cross sections of the trunk-commencing at the stump height and sawn off at intervals of eight feet up to the smallest usable top diameter. A tree that would yield four 8 -foot logs therefore furnishes five disc samples, each about three or four inches thick. The diameter breast-high and the total height of each tree sampled are recorded. The samples necessarily are marked so that material from each tree may be indentified and segregated for the laboratory tests.

Once in the laboratories in the diameter of each disc is measured so that an adequate picture of the form of each tree is obtained. The number of annual layers in each disc is counted so that the rate of growth is known, and finally the basic specific gravity (green volume and oven-dry weight) is determined for each disc. From the basic specific gravity of the samples it is possible to show the mean density (in pounds of dry wood per cubic foot as felled or in any other desirable units) and the extent and type of the variation from the mean.

Such information may be expressed in various forms. From the point of view of the pulpwood operator it seems desirable to calculate the average density of wood by diameter classes for each stand sampled since this form of averaging the data may be used directly with stand tables in estimating the average density of wood from various localities. Knowing the relative proportion of wood in each diameter class that is cut from a certain area, it is a 
simple matter to assign to the wood of each diameter class its appropriate density and to obtain an average for all the wood from that locality. The desirability of this method is particularly evident in the case of stands of comparatively even age where the trees of small diameter are about as old as the larger trees. Under such conditions the small spruces of slow growth have heavier wood than the large ones since, in spruce, a slow rate of growth tends to produce heavy wood. On this account it is necessary to be on the watch to detect in the pulpwoods any correlation that there may be between log diameter and density of wond.

The tests at the Forest Products Laboratories indicate that wood samples from any site, if arranged in classes according to density, approximate the so-called "normal" distribution. In other words there are a few extremely light samples and a few extremely heavy ones with the bulk of the wood comparatively close to the mean density, which is generally about half-way between the two extremes. On this account the extremely light or heavy samples do not greatly affect the average density, hecause such material is relatively scarce and the light specimens are balanced by an equal amount of heavy ones. In testing white spruce bolts from various localities it has been found that the extreme range in basic specific gravity of the holts may be more than twenty-five percent above and below the mean, but with this extreme range half the specimens have proved to be well within six percent of the mean and the vast majority ( 95 percent) within 17 percent of the mean. By way of illustration an actual shipment of spruce representing the material from one hundred trees averaged about 21.5 pounds of dry wood per cuhic foot half the holts between 20.25 and 22.75 pounds per cubic foot, and 95 per cent of all bolts between about 18 to 25 pounds per cubic foot, a range of 3.5 pounds above and below the mean. The remaining 5 percent of the pieces were within an extreme range of about 17 to 27 pounds of dry wood per cubic foot.

Mention of the common method for indicating the normal variation in density of wood and the presentation of actual figures obtained in testing a site sample of wood suggest possible methods of reporting the significant data of this investigation so briefly outlined.

During the year, pulpwood from some fifty individual stands has been collected from the limits of companies in the Canadian Pulp \& Paper Association and the laboratory work on this material is under way at Ottawa. It is believed that the data from such tests expressed in suitable form should enable woodlands operators to make a close estimate of the mean density of wood from each district or type and thereby obtain better control over the pulpproducing quality of the season's supply of wood as well as an improved criterion of the expense that is justified in logging any district. 